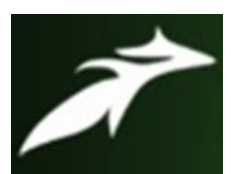

Pramila Tripathi et al, International Journal of Advances in Agricultural Science and Technology,

Vol.7 Issue.11, November-2020, pg. 157-168

ISSN: 2348-1358

Impact Factor: 6.057

NAAS Rating: 3.77

\title{
Advancements in Soil Nutrient Sensing for Real Time Nutrient Management based Recommendation System
}

\author{
Pramila Tripathi ${ }^{1}$; A. K. Shukla ${ }^{2}$ \\ ${ }^{1}$ Department of Botany, D.A.V-P.G. College, Kanpur-208001, India \\ ${ }^{2}$ Department of Botany, Indira Gandhi National Tribal University, Amarkantak-484887, India \\ DOI: 10.47856/ijaast.2020.v07i11.019
}

\begin{abstract}
Rapid soil testing and site specific nutrient management are the keys to improve agricultural production sustainably to feed the growing global population, which is projected to cross 9 billion by the end of 2050. A number of soil nutrient sensors are being developed to meet the demand. This paper is focused on the various recent developments in the field of soil nutrient sensors and their sensitivity for particular nutrients. The incorporation of these sensors to develop agriculture decision support systems is also been discussed. It may be concluded that it is better to integrate a number of sensors (optical and electrochemical) to obtain real time data on nutrient level in soil for a particular cropping season to provide the farmers with a real time report and support. Technologies to convert the results into farmer friendly reports and databases to store the real-time data are also very much essential. The entire study is summarized to have an idea of the development in the field of soil nutrient sensors globally in order to gain insights for the sustainable agricultural production in developing countries, such as India, where cost and population are the governing factors.

Keywords: Nutrient management, soil nutrient sensors, Electro-chemical sensors, sustainable agricultural production, crop specific decision support system
\end{abstract}

\section{Introduction}

The global population is projected to cross 9 billion by the end of 2050 (FAO, 2020) requiring the food production to increase $70 \%$ as compared to the base period in order to feed the global population. Research and development to eradicate global hunger and achieve food security has been extensively discussed and incorporated in the 17 Sustainable Development Goals (UN, 2015). The increased food demand is producing immense pressure on the available land and water resources, which is further exaggerated because of the climate change impacts. Declining the health of soil will affect the overall production in a long run. In addition to this, for the developing and underdeveloped countries, where most of the 850 million people continue to face hunger (FAO, 2020). Laboratory-based soil assessment becomes an expensive task. Farmers, therefore, practice blanket recommendations of fertilizer, mostly based on large-scale soil survey based agro-ecological zoning, rather than site specific and crop specific recommendations based on soil testing. The Imbalanced fertilizer use is one of the primary 


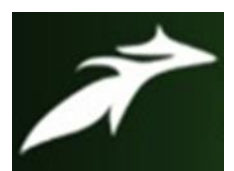

Pramila Tripathi et al, International Journal of Advances in Agricultural Science and Technology, Vol.7 Issue.11, November-2020, pg. 157-168

ISSN: 2348-1358

Impact Factor: 6.057

NAAS Rating: 3.77

causes of soil degradation and adversely influences the environment, human health, and farm profitability.

India, being a developing country with the projection for population to cross China by the year 2025 (UN, 2015), is also facing a similar challenge to meet the food demand through sustainable agriculture. In order to boost site-specific nutrient management under the umbrella of precision farming with the long-term goal to improve soil health, the Government of India had initiated the Soil Health Card (SHC) Scheme in February 2015. SHC is a field specific detailed report of soil fertility status and other important soil parameters that affect crop productivity. It is similar to a physician's prescription, where the health status of the soil is provided and recommendations are made to the farmers accordingly (Trivedi and Dutta, 2020). Details in a SHC includes 12 important parameters such as pH, electrical conductivity (EC), organic carbon, collectively known as soil physical parameters, macronutrients such as nitrogen $(\mathrm{N})$, phosphorus $(\mathrm{P})$, and potassium $(\mathrm{K})$, secondary nutrients such as sulfur $(\mathrm{S})$ and micronutrients such as zinc $(\mathrm{Zn})$, iron $(\mathrm{Fe})$, manganese $(\mathrm{Mn})$, copper $(\mathrm{Cu})$, and boron (B). However, the main drawback in the preparation of SHC is soil sampling by the farmers, which is also a very crucial step for soil testing. Improper soil sampling may not represent the nutrient status of the whole field resulting in faulty recommendations and management, encouraging the farmers to revert to the cultural practices. In addition, the farmers have to waste significant amount of their cultivatable period waiting for the laboratory test results, which most of the time is incomprehensible to them. High demand and limited resources are causing delay and non-uniformity in SHC report generation in India. In order to expedite the process of soil testing, Indian Agricultural Research Institute (ICAR), New Delhi has developed a portable soil kit known as PUSA-STFR (soil test fertilizer recommendation) meter. This kit helps the farmers in testing the 12 important soil parameters mentioned in the SHC in a relatively shorter period and recommends fertilizer dose for 100 crops. Maintaining such kits in Village Community Centers can help in the periodical analysis of soil to achieve the goals of a sustainable agricultural production.

With these emerging technologies, India, despite being a large and populous country, has not only secured self-sufficiency and food security but also positioned itself as an important exporter of agriculture commodities. India is presently leading the world in the production of pulses, jute, and milk. It is also the second-largest producer of rice, wheat, sugarcane, cotton, fruits, and vegetables. However, productivity is low, with yields of all major crops lagging far behind global averages (Padmaja and Reddy, 2018). Undertaking projects that include rapid soil analysis and developing a decision support system (cloud-based using internet of things platform) which could help farmer with field level analysis of nutrient and crop is a need of the hour. With these challenges in mind, the present review consist an overall knowledge on the technologies that have been applied for nutrient analysis globally. The study might act as a guideline to check the feasibility of these techniques under Indian scenario for specific crops, keeping in mind the farm income and limitations. For example, 


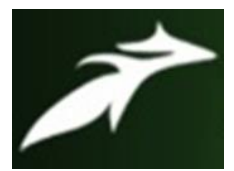

Pramila Tripathi et al, International Journal of Advances in Agricultural Science and Technology, Vol.7 Issue.11, November-2020, pg. 157-168

ISSN: 2348-1358

Impact Factor: 6.057

NAAS Rating: 3.77

remote sensors for time-series data collection, drones and satellites with high-quality cameras for spatial image collection and smart phone apps for real-time control and recommendations are being adapted in developed countries to analyze data and extracted knowledge for a next-generation smart farming (Mirkouei, 2020). The entire review paper is divided into sections describing the current technologies available globally for analyzing the status of nutrient analysis from which we can gain inputs to design a decision support system for sustainable agriculture.

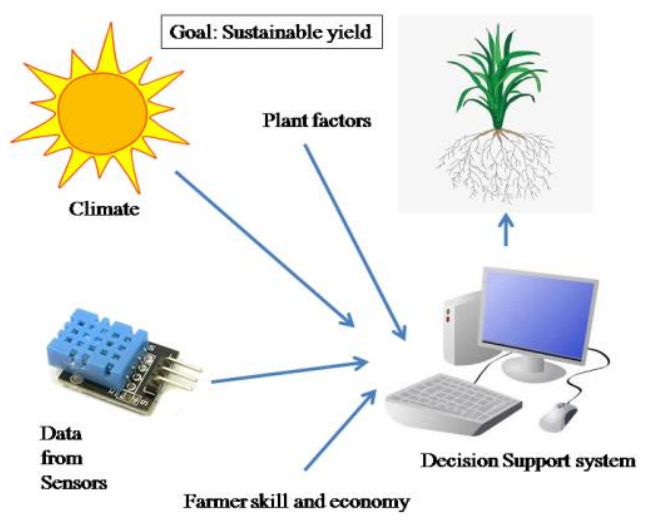

\section{Soil Nutrient Sensors}

Sensors are developed to avoid the classical procedure of time consuming and invasive wet chemistry for soil nutrient detection and to allow for quantification with minimum or no sample preparation (Tavares et al., 2021). Use of sensors in agriculture has begun long back with the measurement of transpiration rates (Briggs and Shantz, 1917). However, advancement in the precision farming and real time nutrient management started with the advancement in technology and communications to develop and transmit sensor data worldwide in a cost effective manner. The sensors are single handheld devices, mobile (Adamchuk et al., 2004) or autonomous (Manderson and Hunt, 2013) using solar energy. Soil nutrient sensing are mostly carried out using optical, electrochemical, and/or colorimetric sensors. In addition, acoustic sensors, pneumatic sensors, electrical and electromagnetic sensors, photoelectron meters, machine vision, satellite imagery, and machine olfaction system to name a few, are suggested to detect the micro nutrient levels in soil. Elaborate reviews of various types of sensors to measure soil properties, including soil nutrients, are available in the literature (Sudduth et al., 1997; Adamchuk et al., 2004; Kim et al., 2009; Burton et al., 2020). In the following sections, we briefly discussed the recent developments in the field of soil-nutrient sensors.

\subsection{Optical sensors:}

Optical sensors uses reflectance spectroscopy to identify the magnitude of reflected and absorbed energy by soil nutrient ions (Burton et al. 2020) and is mostly reported for the three major nutrients, 


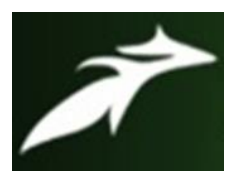

Pramila Tripathi et al, International Journal of Advances in Agricultural Science and Technology, Vol.7 Issue.11, November-2020, pg. 157-168

ISSN: 2348-1358

Impact Factor: 6.057

NAAS Rating: 3.77

$\mathrm{N}, \mathrm{P}$, and $\mathrm{K}$ in soil. There are a number of inventions using spectroscopy to detect nutrient embodied as a portable soil sensor. Bogrekci and Lee (2007) invented a portable Raman sensor for soil P detection in dry as well as wet soil. A $600 \mathrm{~mW}$ laser light source at $785 \mathrm{~nm}$ with a full width at half maximum of about $0.2 \mathrm{~nm}$ and a spectrometer that covers 340 and $3640 \mathrm{~cm}^{-1}$ was used. The program was written in Visual C++ and partial least squares analysis was used to calibrate the model. Rogovska et al. (2019) utilized the potential of diamond-attenuated total internal reflectance (D-ATR) Fourier Transform Infrared (FTIR) spectroscopy as a soil $\mathrm{NO}_{3}$ sensor for rapid field-mobile determination of soil $\mathrm{NO}_{3}$ concentrations. Zhou et al. (2019) developed an optical sensor for in-situ soil total nitrogen and soil moisture detection. The unit is composed of eight single band Near-infrared (NIR) laser sources at $1260,1330,1360,1430,1530,1580,1660$ and $1450 \mathrm{~nm}$. The software part of the program was written in the JN5139 microcontroller unit. Ma et al. (2019) also developed a multichannel, optoelectronic measurement system with automatically switching light sources that consists of peak emission wavelengths of $405 \mathrm{~nm}, 660 \mathrm{~nm}$, and $515 \mathrm{~nm}$, a photodiode array, and a circuit board with a MCU. They used it for the detection of N, P, and K content in six soil samples. Mukherjee and Laskar (2019) reported the design of a portable soil nutrient detector for N, P, and K based on optical sensors and microcontroller. Based on experimentation and analysis, the researchers reported $850 \mathrm{~nm}$ for nitrogen, $620-630 \mathrm{~nm}$ for phosphorous, and $460-470 \mathrm{~nm}$ for potassium analysis for the design. Most of these sensor devices are equipped with farm vehicles to map the variability of soil parameters while traversing the farm terrain (Shibusawa, 2003). Although optical sensors using reflectance spectroscopy changes with the nutrient content in soil, the reflectance signatures varies with the soil type making it challenging to calibrate the model for quantification. Therefore, it is challenging to obtain consistently good estimates across range of soils (Thomasson et al., 2001).

\subsection{Electrochemical sensors:}

Electrochemical sensors use ion-selective electrodes (ISE) and ion-selective field effect transistors (ISFET) that generate a voltage or current output in response to the activity of selected ions. As the name suggests, the ion-selective field effect transistors combines the technologies ion-selective electrodes and field effect transistors. The use of ion-selective electrodes for the measurement of $\mathrm{pH}$ and electrical conductivity (EC) is well established and extensively used, electrochemistry is also being used for decades for the detection of other available soil nutrients for e.g. Orion nitrate ion electrode (model 92-07). Although, relatively large amount of variation are reported to present among multiple measurements of the same sample e.g. $\mathrm{NO}_{3}$ with ion selective electrodes, these are very efficient because they have rapid response, are small and portable, and can perform on-site monitoring of a large number of soil samples (Carey and Riggan, 1994) and are being rapidly modified and developed. The electrodes are currently available for most of the important soil nutrients including $\mathrm{NO}_{3}, \mathrm{~K}$, sodium ( $\mathrm{Na}$ ), and calcium (Ca). However, the identification of a specific sensing material (i.e., ionophore) for the selection recognition of a specific nutrient is a challenging task, particularly 


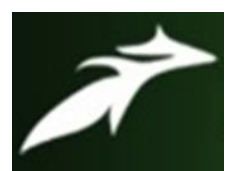

Pramila Tripathi et al, International Journal of Advances in Agricultural Science and Technology, Vol.7 Issue.11, November-2020, pg. 157-168

ISSN: 2348-1358

Impact Factor: 6.057

NAAS Rating: 3.77

because of the interference of other similar ions present in the soil. A number of works are, therefore, dedicated towards selecting the appropriate ion-selective electrode for the particular nutrient. Kim et al. (2007) fabricated and validated the performance of three types of phosphate ISEs and investigated the sensitivity and selectivity responses of the electrodes when using the Kelowna soil extractant $(0.25$ mol L-1 $\left.\mathrm{CH} 3 \mathrm{COOH}+0.015 \mathrm{~mol} \mathrm{~L}^{-1} \mathrm{NH}_{4} \mathrm{~F}\right)$. They observed that the cobalt rod-based electrodes exhibited the highest sensitive responses over a range of $10^{-5}$ to $10^{-1} \mathrm{~mol} / \mathrm{L}$ (typically found in agricultural soil) of total phosphate concentration with a detection limit of $10^{-5} \mathrm{~mol} / \mathrm{L}$ and a rapid response time of $<15$ $s$ when tested in the Kelowna solution. In addition, the selectivity of the electrodes was satisfactory for measuring phosphates in the presence of each of six possible interfering ions, i.e., $\mathrm{HCO}_{3}{ }^{-} \mathrm{Cl}^{-}, \mathrm{Br}^{-}$, $\mathrm{NO}_{3}{ }^{-}, \mathrm{Ac}^{-}$, and $\mathrm{F}^{-}$. Dam and Zevenbergen (2019) reported the development of a miniaturized sensor with a $\mathrm{NO}_{3}{ }^{-}$selective electrode for quick $\mathrm{NO}_{3}{ }^{-}$detection. It was made from a stack of $\mathrm{AgCl}$ electrode, screen printed on polyethylene terephthalate foil, internal electrolyte layer of cellulose gel loaded with $\mathrm{NaNO}_{3}$, and nitrate-selective membrane casted directly on the cellulose gel layer. The flexible electrode showed a sensitivity of $\left.54 \mathrm{mV} / \mathrm{p}^{2} \mathrm{NO}_{3}{ }^{-}\right]$in a nitrate concentration range from 0.1 to $100 \mathrm{mM}$ showed low cross sensitivity to $\mathrm{H}_{2} \mathrm{PO}_{4}{ }^{-}, \mathrm{CO}_{2}{ }^{2-}$ and $\mathrm{SO}_{4}{ }^{2-}$ (below $2.3 \mathrm{mV} / \mathrm{dec}$ ). In addition to the individual ion detection, arrays of ion-selective electrodes have also been used to simultaneously detect a number of nutrients in soil solution. Kim et al. (2007) reported a sensor array of three different ion selective electrodes based on TDDA-NPOE and valinomycin-DOS membranes and Cobalt rod for the simultaneous determination of $\mathrm{NO}_{3}$, phosphate, and $\mathrm{K}$ ions in soil for 37 different Missouri and Illinois soils extracted with the Kelowna extractant. Tregoning (2019) reported an elaborate study on the characterization of ion selective electrodes for on field nutrient analysis. After a number of experiments and analysis, he concluded that the N32.6 nitrate electrodes performed with reasonable selectivity for the interfering phosphate, sulfate, and carbonate ions. He also suggested that the manufacturing process needs to be updated to include conditioning the ion selective electrodes in strontium chloride to improve its stability. Choosang et al. (2018) reported the simultaneous detection of ammonium and nitrate in water and soil using an ion selective electrode and compared the results with colorimetric assays. They used a poly (methyl methacrylate)/poly(decyl methacrylate) copolymer as matrix materials and reported their functionality to detect $\mathrm{NH}_{4}{ }^{+}$- and $\mathrm{NO}^{-}$-selective electrodes by analyzing 8 water and 15 soil samples. The results showed excellent correlation with that obtained using colorimetric assay (Pearson's $\mathrm{R}=0.97$ and 0.99 for $\mathrm{NH}_{4}{ }^{+}$- and $\mathrm{NO}^{-}$ions, respectively). Smolka et al. (2017) developed microfluidic chip for the simultaneous detection of $\mathrm{NO}_{3}, \mathrm{NH}_{4}, \mathrm{~K}$, and $\mathrm{PO}_{4}$ in which the sample ions are separated in an electric field using capillary electrophoresis and the individual ion concentrations are detected by a conductivity measurement. Xu et al. (2016) reported a similar work. They developed an electrophoresis based microfluidic ion nutrient sensor for the detection of anions in soil solution samples using a polydimethylsiloxane-glass electrophoretic microchip. Recently, Chen et al. (2020) reported an all-solid-state ion selective electrode for the detection of nitrate with a 


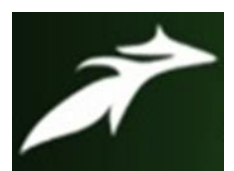

Pramila Tripathi et al, International Journal of Advances in Agricultural Science and Technology, Vol.7 Issue.11, November-2020, pg. 157-168

ISSN: 2348-1358

Impact Factor: 6.057

NAAS Rating: 3.77

nanohybrid composite film of gold nanoparticles (AuNPs) and electrochemically reduced graphene oxide (ERGO), which illustrated a detection range from $10^{-1}$ to $10^{-5} \mathrm{M}$, a response time of about $10 \mathrm{~s}$ and a life time of about 65 days. The recent research towards the development of all-solid-state ion selective electrodes would further benefit in its miniaturization and automation as the need for an internal reference electrode will be eliminated. Zeng and Qin (2020) reported the development of a solid-contact calcium ion-selective electrode with a new inorganic redox buffer- $\mathrm{Ag} @ \mathrm{AgCl} / 1$ tetradecyl-3-methylimidazolium chloride (TMMCl) as the ion-to-electron transducer. An integrated allsolid-state, polymer membrane-based ion-selective-electrode was recently designed and fabricated (Chen et al., 2020). The device includes an on-chip Pt pseudo-reference electrode and three independent $\mathrm{Au}$ working electrodes. Nitrate, potassium, and phosphate selective membranes are coated on the three electrodes independently. In addition to these three macronutrients, i.e., NPK, sensors are also developed and deployed for the detection of micronutrients. Ayranci and Ak (2019) developed a pyrene-substituted poly (2,5-dithienylpyrrole)-based electrode for the sensing and detection of iron (III) ions with a detection limit of $1.73 \times 10^{-7} \mathrm{M}$. The recent developments are a step towards achieving the required pace of nutrient detection for an improved sustainable agricultural production.

\section{Soil pH based sensing of soil nutrients}

The availability of various nutrients, particularly $\mathrm{N}, \mathrm{P}$, and $\mathrm{K}$ depends on the activity of hydronium ions in a solution. The $\mathrm{pH}$ electrodes were, therefore, extensively used for a rapid sensing of nutrient status in the soil and is been utilized for the development of real time soil fertility analyzers. The equivalent $\mathrm{N}, \mathrm{P}$, and $\mathrm{K}$ content of the soil is determined from the $\mathrm{pH}$ to NPK conversion chart (Reddy et al., 2018) where the contents are displayed as High, Medium and Low. Although the $\mathrm{pH}$ to nutrient conversion chart gives the values for Sulphur (S), Calcium (Ca), Magnesium (Mg), Iron (Fe), Zinc(Zn), Iron(Fe), Manganese (Mn), Boron(B), Copper(Cu), and Molybdenum (Mo) as a function of optimal pH, however, the chart is used for the determination of the availability of $\mathrm{N}, \mathrm{P}, \mathrm{K}$ to a large extent in reported studies. On the basis of the pH values, Vadalia et al. (2017) proposed a system that would tests multiple soil samples and obtain an average value of nutrients for a particular field. The results would be displayed on a screen, which the farmer would enter in his mobile application to generate a soil efertility report. The $\mathrm{pH}$ based nutrient analysis was carried a step forward by devising an automated fertilization unit using analog $\mathrm{pH}$ sensor and Arduino. The working principle is quite simple. The difference between the ideal $\mathrm{pH}$ and the $\mathrm{pH}$ value of the soil sensed by the electrode is converted to a deficient amount of $\mathrm{N}, \mathrm{P}$, and $\mathrm{K}$ in soil. The exact deficient value of fertilizer is then calculated by the controller the solenoid valve is opened for the flow of the fertilizer to be pumped and sprinkled. Arduino monitors the switching operation of the solenoid valve at regular intervals to control the amount of fertilizer solution to be pumped with respect to the change in the $\mathrm{pH}$. As the $\mathrm{pH}$ sensor 


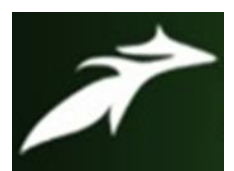

Pramila Tripathi et al, International Journal of Advances in Agricultural Science and Technology, Vol.7 Issue.11, November-2020, pg. 157-168

ISSN: 2348-1358

Impact Factor: 6.057

NAAS Rating: 3.77

generates a voltage due to ionic reactions in millivolts, a driver circuit with an instrumentation amplifier is also used to amplify the voltage so that the controller can read it. Reddy et al. (2018) also developed an automatic irrigation and soil quality testing where the $\mathrm{N}, \mathrm{P}$, and $\mathrm{K}$ sensing was conducted using a TCS230 colour sensor. The colour ranges of the soil solution are defined using an arduino code, which runs on the output of the colour sensor to determine the $\mathrm{pH}$ of the soil. The equivalent NPK content of the soil is determined from the $\mathrm{pH}$ to NPK conversion chart.

\section{Technologies to utilize the results of colorimeter for nutrient analysis}

A number of studies focus on increasing the interpretation of already developed soil kits for nutrient analysis. Puno et al. (2017) utilized image processing and artificial neural network to determine the nutrient and $\mathrm{pH}$ level in soil based on the changes in the color of the chemical present in soil kits after reacting with the soil. They developed a program that will give soil $\mathrm{pH}, \mathrm{N}, \mathrm{P}, \mathrm{K}, \mathrm{Zn}, \mathrm{Ca}$, and $\mathrm{Mg}$ using image processing and artificial neural network using MATLAB programming environment. One of the future scopes of their work was mentioned as having a crop specific fertilizer recommendation system based on the result of the soil testing. A previous work reported by Regalado and Cruz (2016) utilized the soil test kit and used color sensors to measure the RGB values of the colors. The study also tried to eliminate the lighting and distance effect using a fixed distance from an origin. The device was composed of one digital color detector and a Light Dependent Resistor - Red Green Blue Light Emitting Diode color sensor for the color analysis of the soil. The system was microcontroller-based using Arduino and had data storage for future use. The stored data was processed using a program written in vb.net, which provided the analysis and the recommendations of fertilizer. The recommendations were given on the basis of Soil pH, Nitrogen, Phosphorus, and Potassium measured by the system. Recently, Golicz et al. (2019) showed that the smart phone app Akvo Caddisfly could replace the expensive reflectometers that are provided as a part of the test strips. The researchers used the app to replace the Quantofix Relax Reflectometer generally provided with Quantofix test strips and obtained satisfactory results particularly for the quantification of plant available nitrate. Moonrungsee et al. (2015) developed an "Android mobile phone" based colorimetric analyzer that is field deployable for faster and cheaper determination of $P$ in soil. The classic reaction of the orthophosphate, ammonium molybdate, and potassium antimonyl tartrate to form phosphomolybdic acid that is reduced by ascorbic acid to produce the intense colored molybdenum blue was used. The picture of the solution was taken in a light tight box with LED source and a software program was written analyzing RGB color of the picture. A standard graph for $P$ was used to quantify the $P$ present in a particular soil solution. A recent development in the field of nutrient analysis is the development of a microfluidic environment by mixing the reagent with the sample in the micro-channels that enable the use of small volumes of reactant solutions, large surface-to-volume ratio, high efficiency, and repeatability. Dudala et al. (2020) mixed the Griess reagent (1\% sulphanilamide and $0.1 \% \mathrm{n}$-(1- 


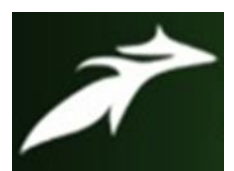

Pramila Tripathi et al, International Journal of Advances in Agricultural Science and Technology, Vol.7 Issue.11, November-2020, pg. 157-168

ISSN: 2348-1358

Impact Factor: 6.057

NAAS Rating: 3.77

naphthyl) ethylenediamine dihydrochloride in $5 \%$ polyphosphoric acid) with filtered soil solution to detect nitrite in micro-channels using LED and photodiode. The flow control was achieved using a lowcost 3D printed syringe pump. In addition, Atmega 328P (onboard Arduino Uno) was used to integrate the subsystems and a smartphone application was built to control the system and store geotagged data.

In the above section, particulars of various sensors are given that are being developed recently with the aim of site selective nutrient management. The next step towards achieving a sustainable smart agriculture would be to incorporate the sensors into a nutrient management system.

\section{Site specific nutrient management systems}

Precision nutrient management and use of ion-selective electrodes to deliver exact quantitiy of deficient fertilizers are being practiced in hydroponics. Kim et al. (2013) developed a nutrient management system using ion selective electrodes to measure the concentration of $\mathrm{N}, \mathrm{K}$ and $\mathrm{Ca}$ ion in hydroponics system and supplied the deficient nutrients. Recently, Ban et al. (2020) reported an improved hydroponic nutrient management system that performs fully automated 3-point calibration 24 times a day to ensure the sensitivity of the sensors. In addition, a machine learning algorithm is applied on the sensory parts to remove ion interference effect in the system. Similar site specific nutrient management strategies using calibrated sensors are required for land crop production, however, the automation would be a difficult task. In addition, a number of factors such as climate, soil characteristics, field infrastructure, and crop characteristics are required to be considered. Therefore, a proper nutrient management for a sustainable crop growth would require a complete decision support system which monitors the nutrient level regularly using sensors and incorporates the local climatic condition and crop characteristics as well. The Leibniz Institute of Vegetable and Ornamental Crops (IGZ) in accordance with the Fertilizer Ordinance 2017 published a program named

"N-Expert - Fertilization Advice and Nutrient Balancing in Field Vegetable Farming" that supports growers to calculate fertilizer demand of vegetable crops and compiles nutrient balances for vegetables. It also includes an up-to-date database for information on nutrient requirements ( $N, P, K$, and $\mathrm{Mg}$ ) for important vegetable species. Zhang and Wen (2017) developed an internet of things (IOT) based system for the moisture and nutrient monitoring of a citrus orchard in China. The entire realtime monitoring system is divided into perception layer, network transmission layer, information service layer and application layer and the loT platform design is applied for the system. Among these, the perception layer is mainly the data acquisition layer, which used several real time soil moisture, humidity, and nutrient sensors to create a database. According to soil moisture and nutrient status, fruit growers obtain the citrus fertilization irrigation support decision based on decision support models. The researchers are further working to reduce the cost of the entire system. Similar systems which integrates data acquisition using various state-of-the-art sensors along with the terrain, climate, 


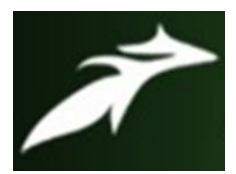

Pramila Tripathi et al, International Journal of Advances in Agricultural Science and Technology, Vol.7 Issue.11, November-2020, pg. 157-168

ISSN: 2348-1358

Impact Factor: 6.057

NAAS Rating: 3.77

and crop properties is required to be developed in a cost effective manner, particularly for developing agriculture based countries, to achieve sustainable crop production.

\section{Conclusion and remarks}

This review is dedicated towards compiling the recently developed soil nutrient measurement devices and the various technologies that uses the output of these devices. It can observe that different sensors are sensitive to the measurement of different parameters in soil. For example, $\mathrm{pH}$ and EC are best measured using ion selective sensors. Whereas, quintoflix test strips with an android based mobile application is providing satisfactory measurement of soil $\mathrm{NO}_{3}$ level at a low cost. Colorimeter based soil kits results are being analyzed to obtain exact quantification of many nutrients, such as $P$. Therefore, it is best to integrate a number of sensors to obtain real time data on nutrient level in soil for a particular cropping season to provide the farmers with a real time report and support. Bramley and Ouzman (2018) reported a very interesting study towards the attitude of growers towards the various decision support systems for nutrient recommendation in Australia. Similar surveys are quite necessary and fruitful for the proper implementation of site specific nutrient management in India as farmers are the driver force of the whole system and where cost is a major constraint.

\section{References}

[1] Adamchuk VI, Hummel JW, Morgan MT, Upadhyaya SK. (2004). On-the-go soil sensors for precision agriculture. Computer and Electronics in Agriculture. 44: 71-91.

[2] Ayranci R, Metin AK. (2019). An electrochemical sensor platform for sensitive detection of iron (III) ions based on pyrene-substituted poly (2, 5-dithienylpyrrole)." Journal of the Electrochemical Society. 166 (6): B291-296.

[3] Ban B, Lee J, Ryu D, Lee M, Eom TD. (2020). Nutrient solution man-agement system for smart farms and plant factory. 2020 international conference on information and communication technology convergence (ICTC). IEEE, New York, pp 1537-1542. doi:10.20944/preprints202005.0381.v1

[4] Bogrekci I, Lee WS. (2007). Comparison of ultraviolet, visible, and near infrared sensing for soil phosphorus Biosystems engineering 96 (2), 293-299.

[5] Boopathy EV, Sathya S, Vennila R, Subhasree P, Swathi S. (2019). High Efficient loT based modern soil composition identifier for smart yield farming. Journal of Physics Conference Series, 1362, 012005: 1-5. doi:10.1088/1742-6596/1362/1/012005

[6] Bramley RGV, Ouzman J. (2019). Farmer attitudes to the use of sensors and automation in fertilizer decision-making: Nitrogen fertilization in the Australian grains sector. Precision Agriculture 20(1):157-175. 


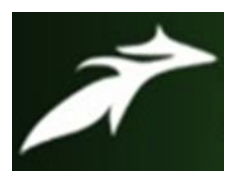

Pramila Tripathi et al, International Journal of Advances in Agricultural Science and Technology, Vol.7 Issue.11, November-2020, pg. 157-168

ISSN: 2348-1358

Impact Factor: 6.057

NAAS Rating: 3.77

[7] Briggs $\amalg$, Shantz HL. (1917). Comparison of the hourly evaporation rate of atmometers and free water surfaces with the transpiration rate of Medicago sativa. Journal of Agricultural Research 9: 277-292.

[8] Burton L, Jayachandran K, Bhansali S. (2020). The "Real-Time" Revolution for In situ Soil Nutrient Sensing: A Review. Journal of The Electrochemical Society. 167(3): 1-8.

[9] Carey, CM, Riggan WB. (1994). Cyclic polyamine ionophore for use in a dibasic phosphate-selective electrode. Analytical Chemistry 66 (21) 3587-3591.

[10] Chen S, yuan B, Liu G, Zhang D. (2020). Electrochemical Sensors Based on Covalent Organic Frameworks: A Critical Review. Frontiers in Chemistry 8: 601044. doi.org/10.3389 /fchem.2020.601044

[11] Choosang J, Numnuam J, Thavarungkul P, Kanatharana P, Radu T, Ullah S, Radu A. (2018). Simultaneous detection of ammonium and nitrate in environmental samples using on ionselective electrode and comparison with portable colorimetric assays. Sensors 18(10): 3555; doi.org/10.3390/s18103555

[12] Dam VAT and Zevenbergen MAG. (2019). Low Cost Nitrate Sensor for Agricultural Applications. 20th International Conference on Solid-State Sensors, Actuators and Microsystems \& Eurosensors XXXIII (Transducers and Eurosensors xxxiii). doi: 10.1109/transducers. 2019.8808327

[13] Dudala S, Srikanth S, Dubey SK, Javed A, Goel S. (2020). Development of Miniaturized Interdigitated Electrode Sensors and Their Application in Taste Sensing. The Electrochemical Society Transactions; 98 (12): 49.

[14] FAO. The State of Food Security and Nutrition in the World 2020. 2020. http://www.fao.org , documents > card.

[15] Golicz, K, Hallett SH, Sakrabani R, (2019). The potential for using smartphones as portable soil nutrient analyzers on suburban farms in central East China. Science Reporter 9: 16424. doi.org/10.1038/s41598-019-52702-8

[16] Kim DJ, Ferrin DL, Rao HR (2009) Trust and satisfaction, the two wheels for successful ecommerce transactions: a longitudinal exploration. Information System Research 20(2):237-257.

[17] Kim HJ, Hummel JW, Sudduth KA, Birrell SJ. (2007). Evaluation of Phosphate Ion-Selective Membranes and Cobalt-Based Electrodes for Soil Nutrient Sensing. Transactions of the ASABE. 50(2): 415-425. doi: 10.13031/2013.22633

[18] Kim HK, Park SJ, Han JI, Lee HK. (2013). Microbially mediated calcium carbonate precipitation on normal and lightweight concrete.Construction and Building Materials. 38: 1073-1082.

[19] Ma L, Zhenfeng L, Zephania B, Shixin L, Yatao Y, Zhang W, Jiandong H. (2019). Multi-Channel Optoelectronic Measurement System for Soil Nutrients Analysis. Electronics. 8: 451-462.

[20] Manderson A, Hunt, C. (2013). Introducing the Agri-Rover: An Autonomous on-the-go sensing rover for science and farming. In Proceedings of the 26th Annual Farmed Landscapes Research 


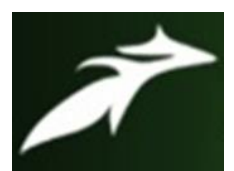

Pramila Tripathi et al, International Journal of Advances in Agricultural Science and Technology, Vol.7 Issue.11, November-2020, pg. 157-168

ISSN: 2348-1358

Impact Factor: 6.057

NAAS Rating: 3.77

Centre Workshop, Palmerston North, New Zealand, 12-14 February; Currie, L., Christensen, C.L., Eds.; Massey University: Palmerston North, New Zealand, 2013.

[21] Mirkouei A. (2020). A Cyber-Physical Analyzer System for Precision Agriculture. Journal of Environmental Sciences and Current Research. 3:16 doi:10.24966/ESCR-5020/100016

[22] Moonrungsee N, Pencharee S and Jakmunee J. (2015). Colorimetric analyzer based on mobile phone camera for determination of available phosphorus in soil. Talanta. 136:204-209. doi: $10.1016 /$ j.talanta.2015.01.024

[23] Mukherjee S and Laskar S. (2019). Vis-NIR-based optical sensor system for estimation of primary nutrients in soil. 2019; 48: 87-103.

[24] Padmaja B, Reddy M. (2018). Drip Irrigation and Fertigation Effects on Aerobic Rice (Oryza sativa) in Semi-Arid Conditions of Telangana State, India. International Journal Current Microbiology and Applied Science 7(8): 1156-1171. doi.org/10.20546/ijcmas. 2018.708.131

[25] Puno JC, Sybingco S, Dadios E, Valenzuela I, Cuello J. (2017). Determination of soil nutrients and $\mathrm{pH}$ level using image processing and artificial neural network. IEEE 9th international conference on humanoid, nanotechnology, information technology, communication and control, environment, and management (HNICEM): 1-6. doi: 10.1109/_hnicem._2017.8269472

[26] Regalado RG, Cruz JD. (2016). Soil pH and nutrient (Nitrogen, Phosphorus and Potassium) analyzer using colorimetry. 2016. IEEE Region 10 Conference (TENCON) P. 2387-2391 doi:10. 1109 /TENCON.2016.7848458

[27] Rogovska N, David AL, Chiou CP, Leonard JB. (2019). Development of field mobile soil nitrate sensor technology to facilitate precision fertilizer management. Precision Agriculture. 20: 40-55. doi.org/10.1007/s11119-018-9579-0

[28] Shibusawa S. (2003). On-line real time soil sensor IEEE/ASME International Conference on Advanced Intelligent Mechatronics (AIM 2003) 2: 1061.

[29] Smolka M, Puchberger-Enengl D, Bipoun M, Klasa A, Kiczkajlo M, Miechowski WS, Sowin ski P, Krutzler C, Keplinger F, Vellekoop MJ, (2017). A mobile lab-on-a-chip device for on-site soil nutrient analysis. Precision Agric 18: 152-168. doi: 10.1007/s11119-016-9452-y

[30] Sudduth KA, Hummel JW, Birrell SJ. (1997). Sensors for site-specific management. In: The State of Site-Specific Management for Agriculture, F.T. Pierce and E.J. Sadler, eds., 1997; 183-210. ASA-CSSA-SSSA, Madison, Wisconsin, USA.

[31] Tavares TR, Molin JP, Nunes LC, Wei MCF, Krug FJ, Carvalho HWP, Mouazen AM. (2020). MultiSensor Approach for Tropical Soil Fertility Analysis: Comparison of Individual and Combined Performance of VNIR, XRF, and LIBS Spectroscopies. Agronomy 11: 1028. doi.org/10.3390/ agronomy 11061028. 


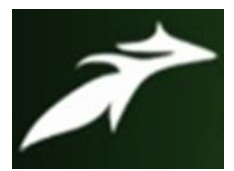

Pramila Tripathi et al, International Journal of Advances in Agricultural Science and Technology, Vol.7 Issue.11, November-2020, pg. 157-168

ISSN: 2348-1358

Impact Factor: 6.057

NAAS Rating: 3.77

[32] Thomasson JA, Sui R, Cox MS, Rajehy AA. (2001). Soil reflectance sensing for determining soil properties in precision agriculture. Transactions of the Americal Society of Agriculture and Biological Engineering. 44(6): 1445-1453 . doi: 10.13031/2013.7002.

[33] Tregoning B. (2019). Characterization of ion-selective electrodes for an on-field soil nutrient analysis system. Thesis: Massachusetts Institute of Technology, Department of Mechanical Engineering, USA.

[34] Trivedi A, Dutta A. (2020). Soil Health Cards: Limitations and Ways to Fix the Loophole. Current Science. 118 (9): 1337-1338.

[35] United Nations. (2015). Sustainable Development Goals, Improving human and planetary wellbeing. 2015; http://www.un.org/sustainabledevelopment/.

[36] Xu Z, Wang X, Weber RJ, Kumar R, Dong L. (2017). Nutrient Sensing Using Chip Scale Electrophoresis and In Situ Soil Solution Extraction. IEEE Sensors Journal 17 (14): 4330-4339.

[37] Zeng X and Qin W. (2020). solid-contact $\mathrm{Ca}^{2+}$-selective electrode based on an inorganic redox buffer of $\mathrm{Ag@AgCl} / 1$-tetradecyl-3-methylimidazolium chloride as ion-to-electron transducer. Talanta 209:120570. doi: 10.1016/j.talanta.2019.120570.

[38] Zhang Y, Wen J. (2017). The IoT electric business model: Using blockchain technology for the internet of things. Peer-to-Peer Netw. Appl. 10: 983-994 doi.org/10.1007/s12083-016-0456-1

[39] Zhou F, Chen J, Tao X, Wang X, Chai YD. (2019). 2D Materials Based Optoelectronic Memory: Convergence of Electronic Memory and Optical Sensor. Sensor Research 2019; 22: 117. doi.org/10.34133/2019/9490413. 